He returned again last November, and a little fulness was then detected about the calcaneo-cuboid joint of the right foot, the one which had ached. Both were put up in plaster-of-Paris for two months, and when these were removed at the beginning of this month the feet looked perfect. The restoration of the arch of the instep was absolutely perfect in this case. In a few of the other patients the plantar arch was restored to perfection. But this was not generally the case. In all it was, however, much improved, and added to the patient's lightness of step, even when to a surgical eye traces of the deformity remained. One of my cases is still under treatment.

Knowing how much the prolonged rest following the operation would of itself tend to improve such cases, and alive to the temptation to be sanguine and over-confident in judging of the results of one's own work, I have endeavoured to free myself from any bias, and to form a true estimate of what was due to the operation itself in the improvement that resulted. Such of the patients as were accessible were seen or written to at considerable periods after the operation, and were warned that the information they gave was required not to gratify me, but to determine whether the same operation should be tried upon others. They all, save the patient mentioned above, maintained that the operation had cured them, and that they would willingly undergo it again on account of the benefit they had derived from it.

My own impression is that this mode of treatment is likely to be of use in suitable cases uncomplicated by other disease, and where none of our other methods can be relied upon. I therefore think it desirable that it should be tested by others, should they deem it worthy of a trial, and receive its verdict according to the results it may yield in their hands.

\section{NOTE ON THE TREATMENT OF FLAT-FOOT.}

BY W. J. WALSHAM, F.R.C.S. ENG.,

ASSISTANT-SURGEON TO, AND SURGEON IN CHARGE OF, THE ORTHOP DEPARTMENT ST. BARTHOLOMEW'S HOSPITAL.

THE boot represented in the accompanying woodcut is one which I have found of much service in the treatment of certain forms of flat-foot in the orthopædic department of St. Bartholomew's Hospital. It differs from the boot with outside leg-iron in ordinary use inasmuch as in place of the T-strap I have substituted a broad band of solid rubber, so

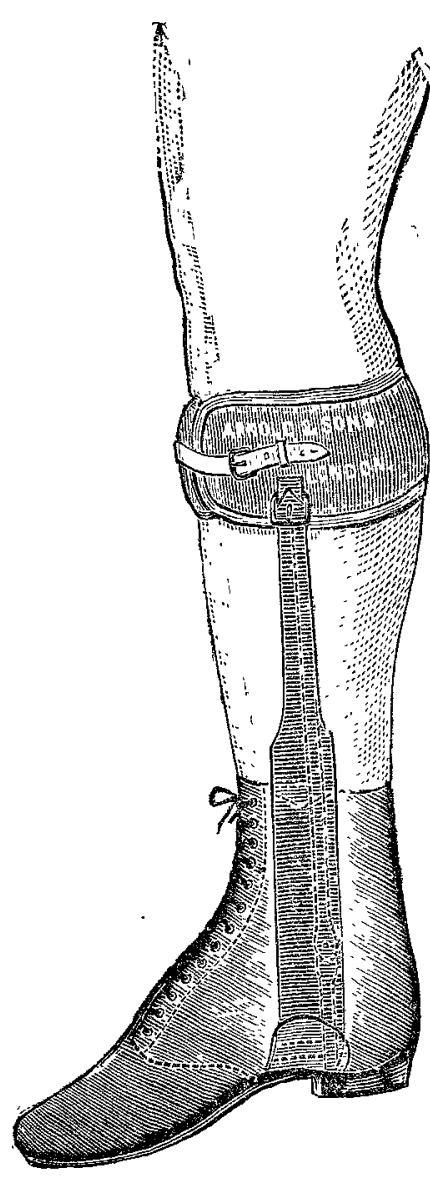
that continuous elastic tension is exercised on the sunken arch. The rubber band is firmly secured to the "uppers" inside the boot along the outer border of the sole in such a position that as it crosses under the sole of the foot its centre corresponds to the middle of the calcaneo-scaphoid ligament. It is then carried up on the inner side of the foot to just above the top of the boot, and thence, through the medium of a leather strap and buckle, secured to the calf-piece. A soft valgus pad is slid over the rubber strap, and so adjusted as to correspond, when in position, to the situation of the yielding arch. In place, therefore, of a passive valgus pad to support the arch, active traction through the medium of the pad is exercised on the depressed bones by the rubber strap. For convenience of treatment ordinary forms of flat-foot may be divided roughly into three degrees. In the first, in which little yielding of the ligaments has taken place, tip-toe exercise, combined with circumduction of the ankle, will generally be found sufficient to produce a cure, if the patient will wear a well-formed laced-up boot with a soft felt valgus pad, and is able to reduce somewhat the hours of standing. In the third form, in which the arch is completely sunken and there is much rigidity of the foot, I know of no treatment which answers so well as that practised by Mr. Willett, and de scribed by him in the eighteenth volume of St. Bartholomew's Hospital Reports-namely, thorough wrenching of the foot under an anæsthetic, and then placing it in a plaster-ofParis case in a position of extreme inversion, with the bones forming the arch forced well into place. In the second form, in which the deformity is well-marked, but is unaccompanied by rigidity, I have obtained the best results by the boot above described. I have tried it now in upwards of a dozen cases, and in every instance the patients have expressed themselves as experiencing great comfort from its use, and have obtained permanen benefit. The boot was first made for me by Messrs. Arnold and Sons, of West Smithfield.

Weymouth-street, $W$.

\section{HAMATOZOA. ${ }^{1}$}

BY T. SPENCER COBBOLD, M.D., F.R.S., F.L.S., Late LeCTURER ON PARASITIC DISEASES AT THE MIDDLESEX hOSPITAK.

Mr. President and Gentlemen,-The subject chosen for consideration this evening is of very great extent, and in dealing with it I shall offer a bird's-eye view of the hæmatozoa as a whole, thereafter selecting $a$ single hæmatozoon for special illustration. Viewing the matter broadly, we may say that there is no class of creatures from the mollusca upwards in which parasites may not be found in the organs of circulation, including within this category the heart and bloodvessels, venous sinuses, and pericardial cavity. Thus von Baer discovered fluke-like parasites (Aspidogaster) in the pericardial chambers of the fresh-water inussel (Anodonta), and he also found a similar kind of entozoon (Histrionella) in the ventricle of the heart of a pond-snail (Paludina.) It is only when we come to the vertebrates that we fully realise the extent to which the organs of circulation may be infested. Larval tapeworms (Tetrarhynchus) have been detected in the heart of a shark (Squalus), and larval flukes (Distoma) have been found encysted in the heart of a viper (Pelias berus) ; but true hæmatozoa, actually circulating in the blood, have also been detected in fishes and frogs. Thus Professor Wedl twice found microscopic nematodes in the blood of the tench (Cyprinus tinca); and Vogt found similar minute hæmatozoa in the blood of a frog, as well as two adult filariæ in the heart of the same batrachian.

When we come to birds then we find the parasites more common. Multitudes of little worms have been discovered in the blood of hawks and jays, in jackdaws and crows, and in other birds. Dr. Sonsino in Egypt, Dr. Lewis in India, and Dr. Manson in China have added largely to our knowledge on this subject. I here show you the hearts of six Chinese magpies (Pica media). Little cysts occur within the pouches of the semilunar valves, and each cyst contains a male and female worm. Dr. Manson dissected some thirty or forty magpies, and in every instance the blood contained quantities of the microscopic offspring of these socalled nlarix picæ medix. About one-third of all the Chinese crows (Corvus torquatus) examined by Manson contained microscopic hæmatuzoa, apparently referable to two distinct species of worms. In a bird from the Malay Archipelago (Goura coronats) he found hæmatozoa resembling filaria sanguinis hominis, and in another bird which is common in China (Gracupica nigricollis) there were hæmatozoa, probably referable to three species of filarix.

When we pass on to the highest vertebrates we can more fully realise the part played by hæmatozoa in the production of disease and even death. The hearts of cetacea, seals, and dogs, especially the latter, are sometimes stuffed with worms. According to Lewis about one-third of the pariah dogs of India are thus affected, and in China and Japan the percentage is probably higher. Here is the heart of a seal (Stemmatopus) containing worms (Filaria hebetata), and here is the heart of a dog showing examples of filaria immitis. At least three species of heinatozoa occur in the dog, and one of them (Spiroptera) gives rise to the formation of tumours

1 An Address delivered at the Middlesex Hospital Medical Society, Jan. 10th, Dr. Arthur W. Edis, F.R.C.P., President, in the chair. 